\title{
O GRANDE DESAFIO DAS INSTITUIÇÕES DE ENSINO SUPERIOR: As práticas pedagógicas criativas são capazes de estimular a inovação nos discentes?
}

THE BIG CHALLENGE FACING HIGHER EDUCATION INSTITUTIONS: Are creative teaching practices capable of stimulating student innovation?

EL GRAN RETO DE LAS INSTITUCIONES DE EDUCACIÓN SUPERIOR ¿Son capaces las prácticas pedagógicas creativas de estimular la innovación en los discentes?

ALESSANDRA CASSOL

Doutoranda

Universidade Nove de Julho - Brasil alessandracassol.adm@gmail.com

RENATA CANELA Mestre

Faculdade de Campinas - Brasil wausma@waus.com.br

ROBERTO LIMA RUAS

Doutor

Universidade Nove de Julho - Brasil roberuas@gmail.com

FLAVIO SANTINO BIZZARIAS

Mestre

Universidade Nove de Julho - Brasil flavioxsp@hotmail.com

JUSSARA GOULART DA SILVA Doutoranda

Universidade Nove de Julho - Brasil jussaragoulart@pontal.ufu.br

Submetido em: 16/11/2014 Aprovado em: 05/09/2015

Doi: alcance.v22n3.p394-409

\section{RESUMO}

A presente pesquisa teve como propósito analisar o papel da inovação no ensino superior por meio das práticas docentes criativas. Utilizou-se da pesquisa quantitativa descritiva, por meio de uma survey com corte transversal e aplicação de questionários estruturados disponibilizados para preenchimento via web em um site especializado em coleta de dados. A amostra foi constituída de 390 estudantes de IES privadas de São Paulo, Minas Gerais e Santa Catarina. A análise estatística foi realizada em duas etapas; a primeira para exploração dos dados e a segunda para a modelagem por equações estruturais para confirmação do modelo teórico proposto. Os principais resultados apontaram para a importância do estímulo à inovação por meio de novas ideias que possam ensejar no aluno um ambiente de reflexão. Esta prática ficou evidenciada nos resultados com a relevância das dimensões Incentivo a Novas Ideias e Clima para a Expressão de Novas ideias.

Palavras-chave: Criatividade. Práticas docentes. Inovação no ensino superior. 


\section{ABSTRACT}

This research examines the role of innovation in higher education through creative teaching practices. It uses descriptive quantitative research, through a cross-sectional survey and structured questionnaires which were filled out on a web site specializing in data collection. The sample consisted of 390 students of private institutions in the states of São Paulo, Minas Gerais and Santa Catarina. The statistical analysis was performed in two stages; the first to explore the data, and the second for the structural equation modeling, to confirm the proposed theoretical model. The main results point to the importance of stimulating innovation through new ideas that can give rise to an environment of student reflection. This practice was evident in the results, with the relevance of the dimensions Incentive for New Ideas and Climate for the Expression of New Ideas.

Keywords: Creativity. Teaching practices. Innovation in higher education.

\section{RESUMEN}

El presente estudio tuvo como propósito analizar el papel de la innovación en la enseñanza superior por medio de las prácticas docentes creativas. Se utilizó la investigación cuantitativa descriptiva por medio de una survey con corte transversal y la aplicación de cuestionarios estructurados para rellenar vía web en un sitio especializado en recolección de datos. La muestra estaba constituida por 390 estudiantes de IES privadas de São Paulo, Minas Gerais y Santa Catarina. El análisis estadístico fue realizado en dos etapas, la primera para exploración de los datos y la segunda para el modelado por medio de ecuaciones estructurales para la confirmación del modelo teórico propuesto. Los principales resultados destacaron la importancia del estímulo a la innovación por medio de nuevas ideas que puedan proporcionarle al alumno un ambiente de reflexión. Esta práctica quedó evidente en los resultados a través de la relevancia de las dimensiones Incentivo a Nuevas Ideas y Clima para la Expresión de Nuevas Ideas.

Palabras clave: Creatividad. Prácticas docentes. Innovación en la educación superior.

\section{INTRODUÇÃO}

No contexto educacional a criatividade assume um papel relevante junto ao processo de inovação. Pesquisadores enfatizam a importância da criatividade e da inovação na economia do conhecimento, caracterizando a economia de hoje como uma economia criativa (HOWKINS, 2002; FLORIDA, 2002; SAWYER, 2006). $O$ ambiente facilitador à criatividade é um dos elementos mais estudados quando se enfoca a evolução da criatividade. Pesquisas têm se voltado para o papel que a educação desempenha no desenvolvimento e no fortalecimento do pensar e agir criativamente (WECHSLER, 2011).

A ação dos docentes possui influência na composição de um ambiente propício para a criatividade e, consequentemente, possui impacto sobre a promoção de estímulos à inovação. Nakano (2009) apontou que as atitudes dos professores influenciam de forma direta na criatividade dos alunos. Pesquisas nacionais e internacionais direcionam para a importância dos professores serem mais criativos, desde os níveis iniciais de escolarização até a universidade, indicando assim a necessidade de maior preparo de docentes (WECHSLER; TREVISAN, 2011; WECHSLER; NAKANO, 2011).

Dentro do atual contexto educacional brasileiro, algumas pesquisas têm sido desenvolvidas com objetivo de compreender o ambiente de educação universitária. Ribeiro e Fleith (2007) examinaram a percepção de professores universitários sobre as práticas docentes que favorecem o desenvolvimento da criatividade nos estudantes. Alencar e Fleith (2010), por sua vez, validaram um instrumento para avaliar a percepção de estudantes universitários com relação aos comportamentos dos professores que favorecem a promoção da criatividade do acadêmico. Fleith (2011) analisou o desenvolvimento da criatividade na cultura brasileira. Essa preocupação com a compreensão sobre 0 ambiente educacional se deve ao fato deste ambiente ser responsável por aperfeiçoar os profissionais que estarão atuando no mercado de trabalho, o qual tem sido cada vez mais exigente e seletivo, buscando por profissionais com capacidade de inovar, solucionar problemas e ser criativo.

Buscou-se compreender como as dimensões das práticas pedagógicas criativas propostas por Alencar e Fleith (2004) utilizadas pelos docentes em IES privadas, e percebidas pelos discentes, são capazes de propiciar o desenvolvimento e a expressão da criatividade do aluno de ensino superior, e estimular 0 
pensamento inovador. Para essa compreensão, inúmeros instrumentos têm sido desenvolvidos nos últimos anos. Entre os instrumentos mais utilizados, segundo Silva e Nakano (2012), há: Inventários de práticas docentes para criatividade (ALENCAR; FLEITH, 2004, 2010), Escala sobre clima para a criatividade em sala de aula (ALENCAR; FLEITH, 2008), Check list de barreiras à promoção da criatividade em sala de aula (ALENCAR; FLEITH, 2008), Testes de Pensamento Criativo de Torrance (TORRANCE, 1999) e Inventário de barreiras à criatividade pessoal (ALENCAR, 1999). Optou-se, para a presente pesquisa, pela utilização do instrumento de Alencar e Fleith (2010), pois ele é específico para análises no meio universitário. Utilizou-se uma survey em IES Privadas de São Paulo, Minas Gerais e Santa Catarina, sendo aplicada em 390 estudantes de graduação de cursos do curso de Administração de Empresas. Como técnica de coleta de dados, utilizou-se o questionário validado na pesquisa de Alencar e Fleith (2010).

Como principais resultados, verificou-se que a escala de Alencar e Fleith (2004) se mostrou válida para aplicação no ensino superior. Foram identificadas todas as dimensões propostas pela escala, com maior importância para os aspectos Incentivos a novas ideias e Interesse pelo aprendizado do aluno. Desta forma, se mostrou que a escala proposta é válida como instrumento de mensuração de um ambiente e de práticas criativas que ensejem a inovação.

Metodologicamente, a pesquisa valida o modelo estrutural para mensuração de práticas docentes e propõe sua relação como antecedente de práticas inovadoras. Por meio da identificação destas práticas, observa-se teoricamente a relação com a inovação no âmbito educacional, pois as práticas docentes, o clima para expressão para novas ideias, o incentivo a novas ideias e a avaliação das metodologias de ensino são capazes de proporcionar o desenvolvimento da inovação no meio acadêmico.

Desta forma, o artigo está estruturado apresentando a sessão de revisão de literatura, em que são apresentados os conceitos de criatividade e os estudos sobre o tema no ensino. Posteriormente, apresenta-se a sessão do método utilizado na pesquisa, os resultados alcançados e, por fim, a discussão dos resultados e as considerações finais.

\section{REVISÃO TEÓRICA}

\subsection{A complementariedade de Criatividade e Inovação}

Com relação aos conceitos de criatividade e inovação, Schumpeter (1982) diferencia o papel da criatividade do da inovação, sendo a criatividade relacionada à criação de ideias, e inovação relacionada ao funcionamento dessas ideias. De acordo com Fontenelle (2012), a criatividade significa criar, inventar; e inovação também pode ser entendida como 0 ato de criar, renovar ou inventar, fazendo algo que já existe de um modo novo, diferente do usual. Torrance (1976) afirma que a criatividade está relacionada à sensibilidade a aos problemas, às lacunas no conhecimento, à identificação de dificuldades e à busca de soluções, formulando proposições acerca dos problemas e comunicando os resultados.

Sobre a inovação, Cros (1997) ressalta que a inovação na maioria dos casos é definida como uma ação ou observada sob o foco de novos produtos. Para Messina (2001), a teoria da inovação, por mais de duas décadas, era conceituada como um processo de etapas sistemáticas desde a implementação até a generalização. Para Fiedler (2011), inovação é uma invenção incorporada aos sistemas, sendo a introdução de uma nova ideia, usando novos conhecimentos. Stoner e Freeman (1999) afirmam que a inovação é uma solução criativa aplicada para problemas e oportunidades detectados pelas organizações. A criatividade implica a geração de uma nova ideia, a inovação se refere à aplicação dessa ideia. Além deste, outros autores evidenciam a relação entre criatividade e inovação, como Pereira Filho (1996), Bruno-Faria e Alencar (1996) e Lemos e Mazzilli (2000). Conforme Janssen (2000) e Scott e Bruce (1994), o comportamento do trabalho inovador consiste na geração de ideias (criatividade), promoção de ideias e implementações de ideias. Terra (2000) menciona que a criatividade está associada ao ponto de partida do processo de inovação. Corroborando Wechsler (2011, p. 38) ressalta que a "criatividade e a inovação são conceitos altamente interligados, pois é impossível a existência de algo diferente e de impacto econômico ou social sem que seja precedida por um processo criativo".

Dentro deste contexto, infere-se que a promoção da criatividade no âmbito do ensino possui forte influência no desenvolvimento de profissionais direcionados para práticas de inovação. 


\subsection{Criatividade no Ensino}

Para inserir criatividade no ensino, existem algumas barreiras e dificuldades. Segundo Ekholm e Kull (1996), o padrão de trabalho do ensino é monótono e as horas em sala de aula são dominadas pelo discurso de professores, na forma de explicar o assunto e, em seguida, fazer perguntas, havendo pouca inovação. Cardoso (1997) afirma que as escolas são dominadas por um padrão de trabalho centrado no professor, o que pode dificultar o surgimento de novas ideias. Além disso, de acordo com Fullan (2000), os professores apresentam uma sobrecarga de tarefas; estão sempre exaustos e sem esperança e têm poucas chances de reflexão. Outro ponto para essa dificuldade, no ambiente das faculdades brasileiras, aponta para falta de interesse em promover a criatividade nos cursos universitários (CASTANHO, 2000). Wechsler (2002) menciona que existem dificuldades para essa inserção no sistema de ensino, tais como falta de preparação dos professores e barreiras internas, que não Ihes permitem ousar e buscar novas estratégias para ensinar. Ribeiro e Fleith (2007) afirmam que os professores percebem a importância da promoção à criatividade, porém possuem dificuldades em adotar estratégias de ensino que favoreçam a criatividade dos alunos. Do mesmo modo, Nakano (2009) menciona que os professores são mal preparados e possuem dificuldades para lidar com as diferenças individuais presentes nos alunos, e que não conhecem sobre estratégias criativas e estimuladoras para ensinar e estão desmotivados com relação às condições institucionais nas quais trabalham.

Entretanto, contra essa dificuldade, Wechsler (2002) e Alencar (2008) apontam para a necessidade de se ter a criatividade inserida como disciplina na formação de professores. Para Messina (2001), os professores devem ser formados para aprender a trabalhar em condições de incerteza e ter confiança nos processos, porém, para mudar, é preciso haver uma proposta de mudança na escola e de promoção de profissionalismo dos docentes. Da mesma maneira, Ribeiro e Fleith (2007) assinalam a necessidade de se repensar a estrutura curricular de cursos do ensino superior de modo a incluir a criatividade como uma ferramenta de trabalho necessária para a formação docente. Assim, cabe à instituição de ensino maximizar as oportunidades de expressão da criatividade nos processos de ensino e aprendizagem (ALENCAR, 2007).

Compreende-se que, por meio do desenvolvimento de práticas que estimulem a criatividade dos discentes, é possível construir ambientes mais propícios para inovação e preparar profissionais qualificados para o mercado de trabalho e para as atuais exigências das empresas.

\subsection{Inovação no Ensino}

Segundo Saviani (1995), há diferentes concepções de inovação, de acordo com as diferentes concepções de filosofia da educação. Na concepção "humanista tradicional", a inovação ocorre de forma acidental. Na concepção "humanista moderna", a inovação está relacionada ao fato de alterar os métodos educacionais. Na concepção "analítica", inovar está relacionado ao fato de usar outras formas, por exemplo, de metodologias. Desta forma, a inovação na educação diz respeito à utilização de outros meios que se acrescentam aos meios tradicionais. Para Cardoso (1997), a inovação é uma mudança deliberada e conscientemente assumida, visando a uma melhoria da ação educativa, inovar no ensino diz respeito a trazer algo efetivamente novo. Observa-se que as instituições de ensino continuam enquadradas num modelo tradicional, destoando-se da dinâmica do mundo. Perrenoud (1999) afirma que no novo modelo de ensino, mais flexível e dinâmico, a construção de práticas e dispositivos alternativos requer intenso trabalho de cooperação e inovação, de ruptura com o individualismo e a rotina.

As inovações educacionais são entendidas como mudanças ocorridas no ensino a partir das ações e das interações dos atores sociais, sendo da instituição e dos seus profissionais. Essas inovações levam à melhora da qualidade para o ensino e à melhora da autonomia da instituição (MITRULIS, 2002). De acordo com Lima (2003), o método Harvard de estudos de casos configura-se como uma forma inovadora de ensino, em que as interfaces hipertextuais possibilitam uma forma de representar várias perspectivas de análise de problemas do cotidiano das organizações. Os estudos de casos permitem desenvolver análise e pensamento crítico, identificação de problemas e tomada de decisão e discernimento entre as possibilidades de resolução, configurando assim como um método que propicia o pensamento criativo do discente.

Veiga et al. (2005) apontam para uma necessidade de gestão mais flexível e que ofereça condições para os docentes de desenvolver autonomia na busca de inovação. Do mesmo modo, cabe ao professor explorar a potencialidade dos discentes, usando técnicas inovadoras adquiridas em treinamentos e programas 
de capacitação, além da própria criatividade. A escola, por sua vez, deve criar espaços para a reflexão, para o exercício da criatividade e da cooperação.

Para Schlemmer et al. (2012), os sistemas de ensino estão em crise e com novas restrições de quantidade, diversidade e velocidade na evolução do saber. Essa instabilidade configura um momento para a inovação, já que há a necessidade de se sair da zona de conforto, criando novas formas de adequação do ensino. Dentro deste contexto, as práticas docentes possuem grande influência para a construção de um ambiente inovador, pois são estimuladores da criatividade, que propicia o desenvolvimento de novas ideias e, consequentemente, de inovações.

No estudo de Alencar e Fleith $(2004,2010)$, foram observados quatro fatores relacionados à criatividade no ambiente de ensino, ressaltando o docente no que diz respeito ao incentivo ou não à criatividade dos alunos. Os fatores extraídos foram: Incentivo a Novas Ideias, Clima para Expressão de Ideias, Avaliação e Metodologia de Ensino e Interesse pela Aprendizagem do Aluno (assim como no estudo de FLEITH, 2011).

Sobre as ações que estimulam a criatividade no ensino, Alencar (2002) assinala para traços de personalidade do docente, tais como autoestima, iniciativa e independência, uso de métodos de ensino e tempo proporcionado ao aluno para refletir e desenvolver ideias novas. Alencar e Fleith (2004), sobre as práticas pedagógicas, notam que o comportamento do professor que estimula a criatividade tende a estimar discussões e debates, incentiva o questionamento e a reflexão, mobiliza o interesse pela aprendizagem do aluno e reforça traços de personalidade como a abertura a críticas e a ideias divergentes. Nakano (2009) observa que 0 professor incentivador de criatividade cria um clima para expressão de novas ideias, encoraja os discentes a aprenderem de forma autônoma e independente do professor. Desta forma infere-se que se cria um ambiente propicio para a inovação. Almeida e Alencar (2010) valorizam o incentivo a novas ideias por meio de inovações realizadas pelos professores a fim desenvolver 0 interesse dos alunos.

Alencar (1995) ressalta que a criatividade do indivíduo tem sido considerada o fator fundamental para a geração da inovação, tornando-se o componente gerador de ideias, enquanto a inovação refere-se à concretização e à aplicação destas.

\section{PROCEDIMENTOS METODOLÓGICOS}

Esta pesquisa se caracteriza como estudo quantitativo e descritivo na medida em que visa observar as relações de um fenômeno específico, apontando seu funcionamento e estabelecendo relações entre as variáveis (MALHOTRA, 2012), sem a pretensão de estabelecer aspectos causais finais.

\subsection{Variáveis do estudo}

Este estudo avalia as práticas pedagógicas criativas em um ambiente de ensino superior - o curso de administração de empresas por meio de um modelo multidimensional. 0 modelo representa apenas a dimensão das Práticas Pedagógicas Criativas e suas relações com as variáveis, sendo: incentivo a novas ideias, clima de expressão a novas ideias, avaliação da metodologia de ensino e interesse pelo aprendizado dos alunos. Estas variáveis compõem o modelo de maneira reflexiva, a Figura 1 apresenta o modelo inicial testado com as hipóteses e as relações previstas. 
Figura 1 - Modelo teórico testado

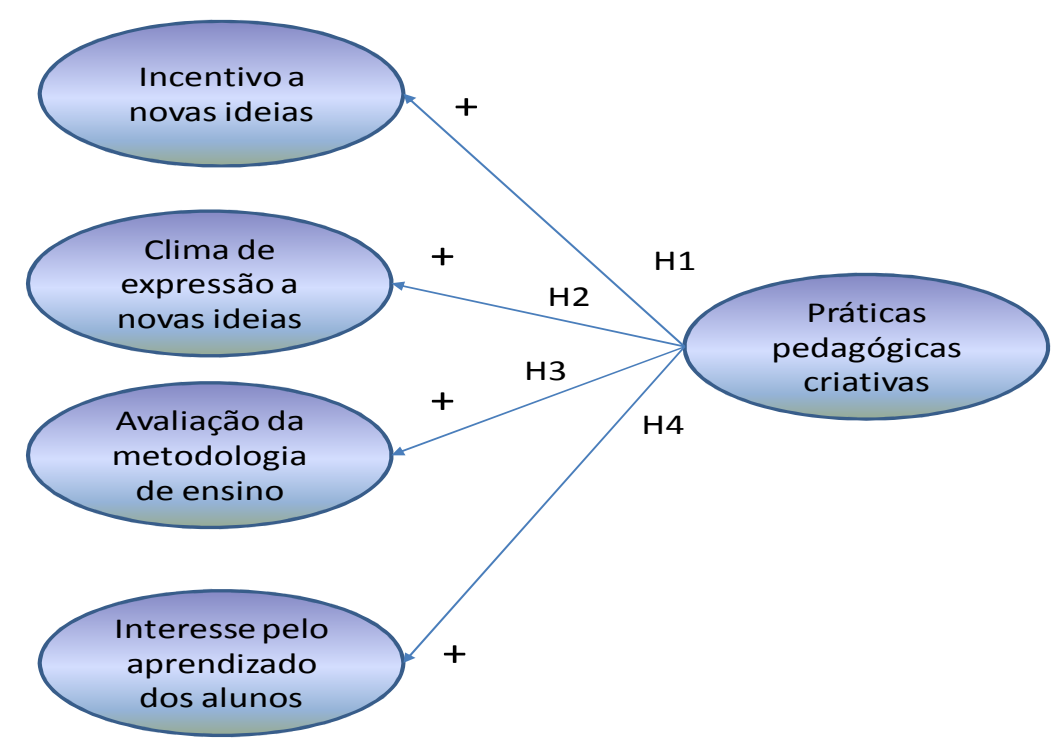

Fonte: Dados da pesquisa (2014).

\subsection{Universo de pesquisa}

O universo de pesquisa foi composto por estudantes universitários do curso de Administração de Empresas de universidades privadas brasileiras, dos estados de Santa Catarina, São Paulo e Minas Gerais. Participaram da pesquisa os acadêmicos das diferentes fases dos cursos, pois o foco foi compreender as práticas docentes relacionadas ao estímulo da criatividade discente, as quais poderiam estar presentes em qualquer momento da formação. A amostra foi aleatória e intencional.

\subsection{Estratégia de coleta de dados}

Para a obtenção dos dados foi realizado um survey com corte transversal e utilização de questionários estruturados disponibilizados para preenchimento via web em um site especializado em coleta de dados. Para a obtenção dos dados com os alunos de diversas turmas, professores foram treinados pelos autores deste estudo a acompanhar os alunos no preenchimento do questionário como atividade complementar nos laboratórios de informática das instituições. Os professores foram informados somente sobre o propósito geral do estudo, o não detalhamento da pesquisa teve como objetivo evitar a possibilidade de influência dos mesmos nas respostas dos investigados. Os alunos foram informados apenas de que se tratava de um estudo acadêmico sem qualquer outra relação com algum aspecto da instituição, buscando evitar possíveis vieses de resposta vinculados a instituição pesquisada.

\subsection{Critérios de análise dos dados}

Os dados foram analisados para se averiguar a normalidade, a homocedasticidade e a ausência de multicolinearidade (VIF < 5). Em seguida, realizou-se a modelagem por equações estruturais (MEE) para a busca da confirmação do modelo teórico proposto. Para a análise preliminar dos dados, utilizou-se o software SPSS 15.0, e para a MEE utilizou-se o software Smart PLS 2.0, indicado para estimação por meio dos mínimos quadrados parciais e amostras sem normalidade identificada (RINGLE; WENDE, 2010).

Na MEE busca-se a validade convergente (cargas superiores a 0,7) e AVE (variância média extraída) superior a 0,5. A validade discriminante se obteve por meio da análise da comparação da raiz quadrada da AVE do construto com a correlação deste com as demais variáveis latentes do modelo. Além disso, efetuou-se análise dos cross loadings, ou cargas cruzadas, com cargas maiores nos construtos que nas demais variáveis para a busca da validade discriminante. Também se verificou 0 índice de adequação geral do modelo denominado Goodness of Fit (GoF), obtido pela média geométrica entre $0 \mathrm{R}^{2}$ médio (adequação do modelo 
estrutural) e a AVE média (adequação do modelo de mensuração). Complementarmente foram realizados os procedimentos de bootstrapping para análise dos coeficientes de caminho onde valores críticos de t de student são 1,64 para $p<0,1,1,96$ para $p<0,5,2,57$ para $p<0,01$, ou para valores abaixo de 1,64 será considerado não significante (n.s.). Por fim, como sugere Hair et al. (2014), observou-se o teste de aderência do modelo e da relevância preditiva dos construtos por meio dos indicadores $Q^{2}$ e f ${ }^{2}$ respectivamente. $O$ teste de blindfoding avalia o valor preditivo do modelo elaborado, onde $Q^{2}>0$ indica que o modelo possui relevância preditiva, e $Q^{2}$ aproximadamente zero, ou menor que zero, indica que não há relevância preditiva. 0 teste $\mathrm{f}^{2}$ avalia quanto 0 construto é útil para a construção do modelo, onde valores de 0,012 ou menos indicam que possui pouca utilidade, 0,15 média utilidade e valores de no mínimo 0,35 indicam grande utilidade (HAIR et al., 2014).

\section{RESULTADOS}

Nesta seção serão apresentados os resultados da fase empírica do estudo.

\subsection{Amostra}

Foram obtidas 390 respostas, e a amostra válida deste estudo é composta de 371 estudantes universitários com idade média de 22,7 anos ( $d p=5,05)$, dos quais $165(44,5 \%)$ são mulheres, $74,1 \%$ são estudantes entre $01^{\circ}$ e $4^{\circ}$ semestres. A escolha deste perfil de amostra se justifica por se tratar de um grupo com capacidade de avaliação referente às práticas docentes aplicadas em sala de aula.

\subsection{Análises prévias do banco de dados}

O exame preliminar dos dados identificou que as variáveis não seguiam uma distribuição normal univariada (teste de Kolmogorov-Smirnov significativo ao nível de $5 \%$ ) e não possuíam padrões de multicolinearidades (VIFs inferiores a 5) (HAIR, 2010). Desta forma, a ausência de normalidade reforçou a decisão da utilização da matriz de correlação para a MEE.

\subsection{Análise dos indicadores de ajuste e dos caminhos estruturais}

A análise do modelo com relação às validades convergente e discriminante indicou a necessidade de eliminação de alguns itens das dimensões da escala de mensuração das práticas pedagógicas criativas. 0 modelo estrutural final ajustado apontou para a permanência de 07 itens da dimensão Incentivo a Novas Ideias, 4 itens da dimensão Clima para Expressão de Novas ideias e 4 itens da dimensão Interesse pela Aprendizagem do Aluno e 3 itens para a dimensão Avaliação de metodologia de ensino. Os itens mantidos no modelo estão indicados nos Apêndices A, em negrito.

Os coeficientes de determinação $\left(R^{2}\right)$ do modelo estrutural final para "Incentivo a Novas Ideias" (89\%), "Clima para Expressão de Novas Ideias" (75,9\%), "Interesse pela Aprendizagem do Aluno"(80,3\%) e "Avaliação da metodologia de ensino" (49,5\%) foram satisfatórios como apontados nos critérios de análise. 0 índice de adequação de ajuste do modelo, $\mathrm{GoF}(0,699)$, foi adequado. Todos os indicadores de ajuste do modelo estão demonstrados no Quadro 1. 
Quadro 1: Indicadores de ajuste do modelo estrutural

\begin{tabular}{|c|c|c|c|c|c|c|}
\hline Construtos & AVE & $\begin{array}{c}\text { Confiabilidade } \\
\text { Composta }\end{array}$ & $\mathbf{R}^{2}$ & $\begin{array}{c}\text { Alpha de } \\
\text { Cronbach }\end{array}$ & Comunalidade & Redundância \\
\hline $\begin{array}{c}\text { Avaliação } \\
\text { metodologia } \\
\text { ensino }\end{array}$ & $0,445^{\star}$ & 0,694 & 0,495 & 0,456 & 0,445 & 0,203 \\
\hline $\begin{array}{c}\text { Clima expressão } \\
\text { novas ideias }\end{array}$ & 0,641 & 0,877 & 0,759 & 0,812 & 0,641 & 0,485 \\
\hline $\begin{array}{c}\text { Incentivo a } \\
\text { novas ideias }\end{array}$ & 0,609 & 0,916 & 0,89 & 0,892 & 0,609 & 0,542 \\
\hline $\begin{array}{c}\text { Interesse } \\
\text { aprendizagem } \\
\text { aluno }\end{array}$ & 0,64 & 0,876 & 0,803 & 0,812 & 0,64 & 0,514 \\
\hline
\end{tabular}

$\mathrm{AVE}_{\text {média }}=0,596 \mathrm{R}_{\text {médio }}=0,737 \mathrm{GoF}=0,667$

*valor abaixo de 0,5, mas considerado aceito neste estudo devido à significância dos itens restantes na explicação do construto (AME1 $t(999)=5,999, p<0,0001$, AME4 $t(999)=26,328, p<0,00001$, AME5 $t(999)=5,824$, $p<0,0001)$.

Fonte: Dados da pesquisa (2014).

Também se observou a validade discriminante no modelo estrutural com as variáveis com itens com cargas maiores nas respectivas variáveis que nas demais variáveis do modelo, como observado no Quadro 2.

\section{Quadro 2: Cross loadings}

\begin{tabular}{|c|c|c|c|c|}
\hline Itens restantes & $\begin{array}{c}\text { Avaliação } \\
\text { metodologia ensino }\end{array}$ & $\begin{array}{c}\text { Clima expressão } \\
\text { novas ideias }\end{array}$ & $\begin{array}{c}\text { Incentivo novas } \\
\text { ideias }\end{array}$ & $\begin{array}{c}\text { Interesse } \\
\text { aprendizagem do } \\
\text { aluno }\end{array}$ \\
\hline AME1 & $\mathbf{0 , 5 4 2}$ & 0,193 & 0,248 & 0,204 \\
\hline AME4 & $\mathbf{0 , 8 7 1}$ & 0,54 & 0,587 & 0,632 \\
\hline AME5 & $\mathbf{0 , 5 3 3}$ & 0,171 & 0,209 & 0,231 \\
\hline CEI1 & 0,434 & $\mathbf{0 , 7 8 4}$ & 0,601 & 0,583 \\
\hline CEI2 & 0,435 & $\mathbf{0 , 8 3}$ & 0,628 & 0,555 \\
\hline CEI3 & 0,389 & $\mathbf{0 , 8 1 6}$ & 0,564 & 0,549 \\
\hline CEI4 & 0,427 & $\mathbf{0 , 7 7}$ & 0,589 & 0,605 \\
\hline IAA11 & 0,5 & 0,646 & 0,64 & $\mathbf{0 , 8 3 7}$ \\
\hline AA12 & 0,441 & 0,574 & 0,626 & $\mathbf{0 , 7 8}$ \\
\hline IAA3 & 0,511 & 0,529 & 0,609 & $\mathbf{0 , 7 9 9}$ \\
\hline IAA7 & 0,53 & 0,539 & 0,589 & $\mathbf{0 , 7 8 4}$ \\
\hline INI10 & 0,464 & 0,581 & $\mathbf{0 , 7 5 2}$ & 0,568 \\
\hline INI11 & 0,477 & 0,611 & $\mathbf{0 , 7 4 7}$ & 0,551 \\
\hline INI2 & 0,441 & 0,554 & $\mathbf{0 , 8 1 4}$ & 0,622 \\
\hline INI4 & 0,46 & 0,574 & $\mathbf{0 , 7 9 5}$ & 0,628 \\
\hline INI5 & 0,466 & 0,536 & $\mathbf{0 , 7 8 9}$ & 0,573 \\
\hline INI6 & 0,47 & 0,575 & $\mathbf{0 , 7 4 6}$ & 0,599 \\
\hline INI9 & 0,456 & 0,636 & $\mathbf{0 , 8 1 8}$ & 0,661 \\
\hline
\end{tabular}

Fonte: Dados da pesquisa (2014).

A análise dos caminhos no relacionamento entre as variáveis no modelo se mostrou significante. Para esta etapa, utilizou-se a reamostragem, ou bootstrap, com 1000 repetições de amostras para identificar a significância das cargas nos caminhos estruturais na relação entre as variáveis. 0 resultado desta etapa está demonstrado no Quadro 3. 
Quadro 3: Análise dos caminhos estruturais do modelo

\begin{tabular}{|c|c|c|c|c|c|c|c|c|}
\hline Hipótese & Sentido & Relação & $\begin{array}{c}\text { Coeficiente } \\
\text { original }\end{array}$ & $\begin{array}{c}\text { Média das } \\
1000 \text { sub- } \\
\text { amostras }\end{array}$ & $\begin{array}{c}\text { Erro } \\
\text { padrão }\end{array}$ & Teste $\mathbf{t}$ & p-value & Resultado \\
\hline P1 & Positivo & $\begin{array}{c}\text { PRÁTICAS } \\
\text { DOCENTES } \\
\text { CRIATIVAS - } \\
\text { Incentivo novas } \\
\text { ideias }\end{array}$ & 0,943 & 0,943 & 0,007 & 126,59 & $p<0,00001$ & Aceita \\
\hline Positivo & $\begin{array}{c}\text { PRÁTICAS } \\
\text { DOCENTES } \\
\text { CRIATIVAS- } \\
\text { Clima expressão } \\
\text { novas ideias }\end{array}$ & 0,871 & 0,871 & 0,015 & 55,424 & $p<0,00001$ & Aceita \\
\hline $\begin{array}{c}\text { PRÁTICAS } \\
\text { DOCENTES } \\
\text { CRIATIVAS - } \\
\text { Avaliação da } \\
\text { metodologia de } \\
\text { ensino }\end{array}$ & 0,703 & 0,708 & 0,027 & 25,545 & $p<0,00001$ & Aceita \\
\hline Positivo & $\begin{array}{c}\text { PRÁTICAS } \\
\text { DOCENTES } \\
\text { CRIATIVAS- } \\
\text { Interesse } \\
\text { aprendizagem } \\
\text { aluno }\end{array}$ & 0,92 & 0,92 & 0,009 & 97,483 & $p<0,00001$ & Aceita \\
\hline
\end{tabular}

Valores críticos de t: 1,64 p<0,1;1,96p<0,5; 2,57 p<0,01 / N.S. = não significante

Fonte: Dados da pesquisa (2014).

Os resultados indicam a validade da aplicação da escala na amostra obtida. O Quadro 4 apresenta os indicadores de relevância preditiva $\left(Q^{2}\right)$ e a importância do construto no modelo (f2).

Quadro 4 - Análise de relevância preditiva e importância do construto

\begin{tabular}{|c|c|c|}
\hline Variável & $\mathbf{Q}^{2}$ & $\mathbf{f}^{2}$ \\
\hline Incentivo a novas ideias & 0,54 & 0,592 \\
\hline Clima para expressão de novas ideias & 0,484 & 0,649 \\
\hline Avaliação da metodologia de ensino & 0,202 & 0,384 \\
\hline Interesse pela aprendizagem do aluno & 0,513 & 0,585 \\
\hline
\end{tabular}

Fonte: Dados da pesquisa (2014).

Estes resultados corroboram o bom ajuste do modelo, exceto pela dimensão Avaliação da Metodologia de Ensino, que obteve pouca utilidade na construção do modelo. A Figura 2 apresenta o resultado final do modelo estrutural. 


\section{Figura 2: Modelo estrutural final}

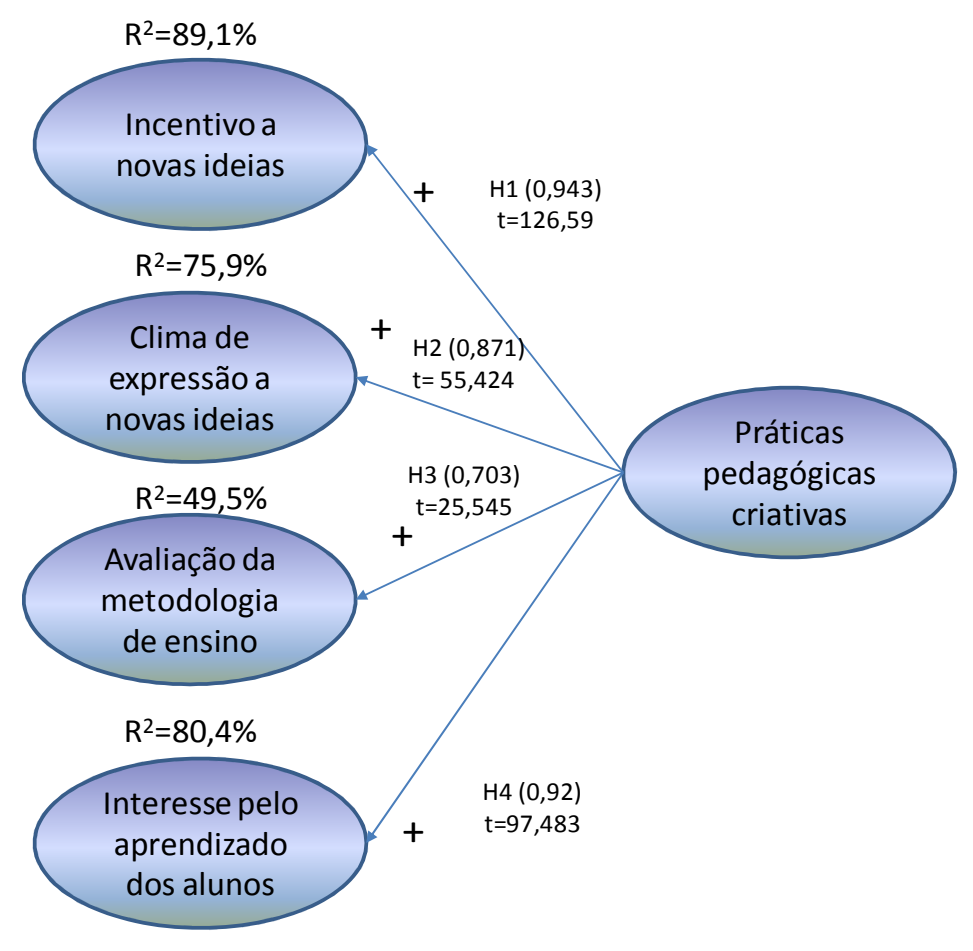

Fonte: Dados da Pesquisa (2014).

Na seção seguinte é apresentada a discussão sobre os resultados obtidos, implicações acadêmicas e gerenciais, bem como sugestão de estudos futuros.

\section{DISCUSSÃO DOS RESULTADOS E CONSIDERAÇÕES FINAIS}

O modelo analisado procurou avaliar a percepção de alunos de administração sobre as práticas pedagógicas criativas. Os resultados indicam que a dimensão de Incentivo a novas ideias foi a dimensão mais bem explicada no modelo $\left(R^{2}=89,1 \%\right)$ com maior força na relação com o construto Práticas pedagógicas criativas $(0,943 ; t(999)=126,598<0,00001)$, seguida pela dimensão Interesse pela aprendizagem do aluno $\left(R^{2}=80,4 \%\right)$, com a segunda maior força do relacionamento $(0,896 ; t(999)=70,568<0,00001)$. A relevância na construção do modelo foi equivalente para estas dimensões ( $f^{2}=0,592$ e $f^{2}=0,585$, respectivamente) e grande valor preditivo para o modelo $\left(Q^{2}=0,540\right.$ e $Q^{2}=0,513$, respectivamente).

A dimensão Clima para Expressão de Novas Ideias se mostrou relevante no modelo $\left(R^{2}=75,9 \%\right.$, $\mathrm{Q}^{2}=0,484$ e $\left.\mathrm{f}^{2}=0649\right)$ por apresentar também forte 0 relacionamento com 0 construto Práticas pedagógicas criativas $(0,871 ; t(999)=55,424 ; p<0,00001)$. A dimensão Avaliação das práticas pedagógicas alcançou resultados satisfatórios $\left(R^{2}=49,5 \%, Q^{2}=0,202\right.$ e $\left.f^{2}=0,384\right)$, com um relacionamento um pouco menos forte que as demais dimensões, porém estatisticamente significante $(0,703 ; t(999)=25,545 ; p<0,00001)$. Estes resultados apontam para a importância do estímulo à inovação por meio de novas ideias que possam ensejar no aluno um ambiente de reflexão. Esta prática ficou evidenciada nos resultados com a relevância das dimensões Incentivo a Novas Ideias e Clima para a Expressão de Novas Ideias.

Ao mesmo tempo, os resultados apontam que os discentes percebem no corpo docente 0 interesse pelo estímulo a um ambiente que enseje o pensar diferente em uma amostra bastante heterogênea. $O$ uso de metodologias adequadas à prática criativa em sala de aula também ficou demonstrada. Conclui-se que a escala de Práticas pedagógicas criativas foi validada, e seus indicadores de ajuste sustentam sua aplicabilidade ensejando um cenário propício à inovação. 


\subsection{Implicações acadêmicas}

Este estudo validou uma escala de avaliação das práticas pedagógicas criativas nos cursos de administração sob a percepção do discente, mostrando que 0 aluno demonstra interesse e reconhece na atuação do docente a fomentação de um cenário propício à inovação por meio do incentivo à expressão e ao clima de novas ideias.

A identificação de instrumentos que possam mensurar questões relacionadas à criatividade é relevante aos estudos acadêmicos, constituindo um paradigma ímpar nos estudos nesta área (STERNBERG; LUBART, 1999). Este estudo contribuiu para a consolidação de um instrumento de mensuração das práticas pedagógicas criativas no ensino superior sob a perspectiva dos discentes, e discutiu como se enseja um ambiente propício à inovação no ensino superior. A inovação e a criatividade são conceitos relacionados, e esta pesquisa propõe que se possa estabelecer uma ponte entre estes construtos de maneira que se possa avançar no estudo da sua relação com o ambiente de ensino.

\subsection{Implicações gerenciais}

A compreensão do funcionamento das práticas pedagógicas criativas em um ambiente de formação de novos gestores permite que as IES possam planejar diversas questões relacionadas aos cursos superiores. Podem-se utilizar os resultados deste estudo para se posicionar uma IES como entidade que fomenta a inovação por meio de um ambiente de ensino criativo, na medida em que os alunos percebem estas características como importantes no ensino de Administração. Desta forma, pode-se então planejar o curso de maneira que todas as disciplinas possam refletir este reconhecimento do discente quanto às práticas pedagógicas criativas. Também se enseja que os professores possam ser estimulados e avaliados pela IES quanto às práticas de ensino que utilizam.

\subsection{Limites e sugestões de estudos futuros}

Por se tratar de um estudo descritivo, sugere-se que se investigue a percepção dos alunos quanto às práticas pedagógicas criativas em outros cursos de uma IES, e então se possam estabelecer comparações. Também se sugere que sejam realizadas pesquisas empíricas para analisar as relações entre inovação e criatividade.

\section{REFERÊNCIAS}

ALENCAR, Eunice ML. Efeitos de um programa de criatividade em alunos de $4 .{ }^{a}$ e $5 .{ }^{a}$ séries. Arquivos Brasileiros de Psicologia Aplicada, v. 27, n. 4, p. 3-15, 2014.

ALENCAR, Eunice ML Soriano. Criatividade no Contexto Educacional: Três Décadas de Pesquisa1. 2007.

ALENCAR, E. M. L. S.; FLEITH, D. De S. Criatividade na educação: elementos inibidores e facilitadores. Educação: tendências e desafios de um campo em movimento, v. 2, p. 75-89, 2008.

ALENCAR, Eunice Lima Soriano de. Desenvolvendo a criatividade nas organizações: 0 desafio da inovação. Revista de Administração de Empresas, v. 35, n. 6, p. 6-11, 1995.

ALENCAR, Eunice ML Soriano. University students' evaluation of their own level of creativity and their teachers' and colleagues' level of creativity. Gifted Education International, v. 11, n. 3, p. 128-130, 1996.

ALENCAR, Eunice ML Soriano. 0 estímulo à criatividade no contexto universitário. 1997.

ALENCAR, Eunice ML Soriano. $O$ estímulo à criatividade em programas de pós-graduação segundo seus estudantes. Psicologia: reflexão e crítica, v. 15, n. 1, p. 63-70, 2002.

ALENCAR, Eunice ML Soriano. 0 curso de Pedagogia e condições para 0 desenvolvimento da criatividade. Psicologia Escolar e Educacional, v. 10, n. 1, p. 21-30, 2006.

ALENCAR, Eunice ML Soriano; DE SOUZA FLEITH, Denise. Inventário de práticas docentes que favorecem a criatividade no ensino superior. Psicologia: Reflexão e Crítica, v. 17, n. 1, p. 105-110, 2004. 
ALENCAR, Eunice ML; FLEITH, Denise de Souza. Escala de práticas docentes para a criatividade na educação superior. Avaliação Psicológica, v. 9, n. 1, p. 13-24, 2010.

ALMEIDA, Alda Rosana; BOTELHO, Delane. Construção de questionários, 2006.

ALMEIDA, Janaina Maria Oliveira; ALENCAR, EMLS de. Criatividade no ensino médio segundo seus estudantes. Paidéia, v. 20, n. 47, p. 325-334, 2010.

AMARAL, Ana Luiza Neiva; MITJÁNS MARTíNEZ, Albertina. Aprendizagem e criatividade no contexto universitário. Psicologia para América Latina, n. 8, p. 0-0, 2006.

BARRETO, Maribel Oliveira; MARTÍNEZ MITJÁNS, Albertina. Possibilidades criativas de professores em cursos de pós-graduação stricto sensu. 2007.

FARIA, Maria de Fátima Bruno; DE ALENCAR, Eunice ML Soriano. Estímulos e barreiras à criatividade no ambiente de trabalho. Revista de Administração da Universidade de São Paulo, v. 31, n. 2, 1996.

CARDOSO, Ana Paula. Educação e inovação. 1997.

CASTANHO, M. E. L. M.; VEIGA, IIma P. Alencastro; CASTANHO, M. E. L. M. A criatividade na sala de aula universitária. Pedagogia universitária. A aula em foco, p. 75-89, 2000.

COTO, Gabriela Cordioli; NETO, Luís Moretto; PACHECO, Andressa Saazaki. Criatividade dentro da Educação: um estudo de caso do Curso de Administração da UFSC-Universidade Federal de Santa Catarina. Revista de Ciências da Administração, v. 11, n. 24, p. 221-245, 2009.

CROS, Françoise. L'innovation en éducation et en formation. Revue française de pédagogie, v. 118, n. 1, p. 127-156, 1997.

CSIKSZENTMIHALYI, Mihaly. Society, culture, and person: A systems view of creativity. Cambridge University Press, 1988.

DEMO, Pedro. Metodologia científica em ciências sociais. 1989.

DIAS, Tatiane Lebre; ENUMO, Sônia Regina Fiorim; AZEVEDO JR, Romildo Rocha. Influências de um programa de criatividade no desempenho cognitivo e acadêmico de alunos com dificuldade de aprendizagem. Psicologia em Estudo, v. 9, n. 3, p. 429-437, 2004.

DUAILIBI, R.; SIMONSEN JR, H. Creatividad \& marketing. 1992.

EKHOLM, Mats; KULL, Magnus. School climate and educational change: Stability and change in nine Swedish schools. Eera Bulletin, v. 2, p. 3-11, 1996.

FELDMAN, David Henry; CSIKSZENTMIHALYI, Mihaly; GARDNER, Howard. Changing the world: A framework for the study of creativity. Praeger Publishers/Greenwood Publishing Group, 1994.

FIEDLER, Ligia. Gestão de Idéias para Inovação Contínua. Revista de Administração Contemporânea, v. 15, n. 1, p. 173-175, 2011.

FLEITH, Denise de Souza; ALENCAR, Eunice Maria L. Percepção de alunos do ensino fundamental quanto ao clima de sala de aula para criatividade.Psicologia em Estudo, v. 11, n. 3, p. 513-521, 2006.

FLEITH, Denise S. Creativity in the Brazilian culture. Online Readings in Psychology and Culture, v. 4, n. 3, p. 3, 2011.

FLORIDA, Richard L. The rise of the creative class: and how it's transforming work, leisure, community and everyday life. Basic books, 2002.

FONTENELLE, Isleide A. Para uma crítica ao discurso da inovação: saber e controle no capitalismo do conhecimento. RAE-Revista de Administração de Empresas, v. 52, n. 1, p. 100-108, 2012.

FULLAN, Michael; STIEGELBAUER, Suzanne. El cambio educativo: guía de planeación para maestros.

México: Trillas, 1997.

GUILFORD, J. P. Creativity. American Psychologist, v. 5, p. 444-454, 1950.

GURGEL, Marcos Freire. Criatividade \& inovação: uma proposta de gestão da criatividade para 0 desenvolvimento da inovação. 2006. Tese de Doutorado. UNIVERSIDADE FEDERAL DO RIO DE JANEIRO. 
HAIR, JOSEPH, HULT, G. Tomas M., RINGLE, Christian, SARSTEDT, Marko. A primer on partial least squares structural equation modelling (PLS-SEM). SAGE Publications, 2014.

HAIR, Joseph. Multivariate Data Analysis 7th Edition. Prentice Hall, 2010.

HALPERN, Diane F. Thinking critically about critical thinking. Instructor\&s manual. Lawrence Erlbaum Associates, 1996.

HOWKINS, John. The creative economy: How people make money from ideas. Penguin UK, 2002.

JANSSEN, Onne. Job demands, perceptions of effort-reward fairness and innovative work behaviour. Journal of Occupational and organizational psychology, v. 73, n. 3, p. 287-302, 2000.

KOZBELT, Aaron; BEGHETTO, Ronald A.; RUNCO, Mark A. Theories of creativity. The Cambridge handbook of creativity, p. 20-47, 2010.

LEMOS, L. A. P.; MAZZILLI, C. Uma análise do processo criativo no trabalho multifuncional: um estudo de caso. ENANPAD - Florianópolis, 2002.

LIMA, Marcos Cerqueira. Estudos de casos hipertextuais: rumo a uma inovação no método Harvard de ensino de gestão. Revista de Administração Contemporânea, v. 7, n. 3, p. 77-99, 2003.

MALHOTRA, Naresh K. Pesquisa de marketing: uma orientação aplicada. Tradução de Nivaldo Montingelli Jr. e Alfredo Alves de Farias. 2001.

MALHOTRA, Naresh K. Pesquisa de marketing: uma orientação aplicada. Bookman, 2012.

MATEOS-APARICIO, Gregoria. Partial least squares (PLS) methods: Origins, evolution, and application to social sciences. Communications in Statistics-Theory and Methods, v. 40, n. 13, p. 2305-2317, 2011.

MESSINA, Graciela. Mudança e inovação educacional: notas para reflexão. Cadernos de Pesquisa, n. 114, p. 225-233, 2001.

MITRULIS, Eleny. Ensaios de inovação no ensino médio. Cadernos de Pesquisa, n. 116, p. 217-244, 2002.

NAKANO, Cássia Tatiana. Investigando a criatividade junto a professores: pesquisas brasileiras. Revista Semestral da Associação Brasileira de Psicologia Escolar e Educacional (ABRAPEE)* Volume, v. 13, n. 1 , p. 45-53, 2009.

PEREIRA FILHO, João Lins. Inovação e criatividade em organizações brasileiras: um estudo piloto de casos nacionais, 1996.

PERRENOUD, P. Construir as competências desde a Escola. Porto Alegre: Artes Médicas Sul, 1999. p. 90.

PFEIFER, Suzana Susi. Criatividade: um estudo nas fronteiras da ciência, da arte e da espiritualidade. Tese de Doutorado. Universidade Federal de Santa Catarina, Centro Tecnológico. Programa de Pós-Graduação em Engenharia de Produção. 2001.

PINSONNEAULT, Alain; KRAEMER, Kenneth L. Survey research methodology in management information systems: an assessment. Journal of management information systems, p. 75-105, 1993.

REIS, Elisabete. Estatística multivariada aplicada. 2001.

RIBEIRO, Rejane Arruda; FLEITH, Denise de Souza. O estímulo à criatividade em cursos de licenciatura. Paidéia, v. 17, n. 38, p. 403-416, 2007.

RICHARDSON, R. J. Pesquisa social: métodos e técnicas. 3. ed. São Paulo: Atlas, 1999.

RINGLE, C. M., WENDE, S. and WILL , A . ( 2005 ) SmartPLS 2.0 (beta) , www.smartpls.de , Hamburg, accessed 2 August, 2010.

RHODES, Mel. An analysis of creativity. Phi Delta Kappan, p. 305-310, 1961.

RUNCO, Mark A. Everyone has creative potential. Creativity: From potential to realization, p. 21-30, 2004.

SANTEIRO, Tales Vilela; SANTEIRO, FR de M.; ANDRADE, IR de. Professor facilitador e inibidor da criatividade segundo universitários. Psicologia em estudo, v. 9, n. 1, p. 95-102, 2004. 
SAVIANI, Dermeval. A filosofia da educação e o problema da inovação em educação. GARCIA, Walter Esteves. Inovação educacional no Brasil: problemas e perspectivas. Campinas: Autores Associados, p. 17-31, 1995.

SAWYER, R. Keith. Educating for innovation. Thinking skills and creativity, v. 1, n. 1, p. 41-48, 2006.

SCHLEMMER, Eliane; GARRIDO, Susane; CALEFFI, Paula. A modalidade de Educação a Distância (sem distância) na UNISINOS: um novo conceito para inovação?. RIED. Revista iberoamericana de educación a distancia, v. 9, n. 1-2, 2012.

SCHUMPETER, Joseph Alois. Teoria do desenvolvimento econômico: uma investigação sobre lucros, capital, crédito, juro e o ciclo econômico. Abril Cultural, 1982.

SCOTT, Susanne G.; BRUCE, Reginald A. Determinants of innovative behavior: A path model of individual innovation in the workplace. Academy of management Journal, v. 37, n. 3, p. 580-607, 1994.

STERNBERG, Robert J.; LUBART, Todd I. The concept of creativity: Prospects and paradigms. Handbook of creativity, v. 1, p. 3-15, 1999.

STONER, J.; FREEMAN, R. E. Administração. 1. ed. Rio de Janeiro, L.T.C., 1999.

TENENHAUS, Michel et al. PLS path modeling. Computational statistics \& data analysis, v. 48, n. 1, p. 159205, 2005.

TERRA, José Cláudio Cyrineu. Gestão da criatividade. Revista de Administração da Universidade de São Paulo, v. 35, n. 3, 2000.

TORRANCE, E. P. Criatividade: medidas, testes e avaliações. São Paulo: IBRASA, 1976.

VEIGA, Laura da; LEITE, Maria Ruth Siffert Diniz Teixeira; DUARTE, Vanda Catarina. Qualificação, competência técnica e inovação no ofício docente para a melhoria da qualidade do ensino fundamental. Revista de Administração contemporânea, v. 9, n. 3, p. 143-167, 2005.

VERGARA, S. C. Projetos e relatórios de pesquisa em administração. 3. ed. São Paulo: Atlas, 2000.

WECHSLER, Muglia. Criatividade e desempenho escolar: uma síntese necessária. Linhas Críticas, v. 8, n. 15, p. 179-188, 2002. 
Apêndice A - Práticas pedagógicas criativas (Alencar; Fleith, 2004)

\begin{tabular}{|c|c|c|}
\hline Código & Item & Dimensão \\
\hline INI1 & Cultiva nos alunos o gosto pela descoberta e busca de novos conhecimentos & \multirow{14}{*}{$\begin{array}{c}\text { Incentivo a novas } \\
\text { ideias }\end{array}$} \\
\hline INI2 & Faz perguntas desafiadoras que motivem os alunos a pensar e raciocinar & \\
\hline INI3 & Estimula os alunos a analisarem diferentes aspectos de um problema & \\
\hline INI4 & Estimula a iniciativa dos alunos & \\
\hline INI5 & Estimula o aluno a pensar ideias novas relacionadas ao conteúdo da disciplina & \\
\hline INI6 & Promove a autoconfiança dos alunos & \\
\hline INI7 & Estimula a curiosidade dos alunos através das tarefas propostas & \\
\hline INI8 & Incentiva a independência dos alunos & \\
\hline INI9 & Desenvolve nos alunos habilidades de análise crítica & \\
\hline INI10 & Leva o aluno a perceber e conhecer pontos de vistas divergentes sobre o mesmo problema ou tema de estudo & \\
\hline INI11 & Incentiva os alunos a fazerem questões relativas aos temas estudados & \\
\hline $\mathrm{INI} 12$ & Apresenta vários aspectos de uma questão que está sendo estudada & \\
\hline INI13 & Promove o debate com estímulo à participação de todos os alunos & \\
\hline INI14 & Faz perguntas, buscando conexões com assuntos abordados & \\
\hline CEl1 & Valoriza as ideias originais dos alunos & \multirow{6}{*}{$\begin{array}{c}\text { Clima para } \\
\text { Expressão de Ideias }\end{array}$} \\
\hline CEI2 & Cria um ambiente de respeito e aceitação pelas ideias dos alunos & \\
\hline CEI3 & Dá chances aos alunos para discordarem de seus pontos de vista & \\
\hline CEI4 & Escuta com atenção as intervenções dos alunos & \\
\hline CEI5 & Não está atento aos interesses dos alunos & \\
\hline CEI6 & Tem senso de humor em sala de aula & \\
\hline AME1 & Preocupa-se apenas com o conteúdo informativo & \multirow{5}{*}{$\begin{array}{l}\text { Avaliação e } \\
\text { Metodologia de } \\
\text { Ensino }\end{array}$} \\
\hline AME2 & Utiliza formas de avaliação que exigem do aluno apenas a reprodução do conteúdo dado em classe ou contido nos livros-texto & \\
\hline AME3 & Utiliza sempre a mesma metodologia de ensino & \\
\hline AME4 & Faz uso de formas diversificadas de avaliação & \\
\hline AME5 & Oferece aos alunos poucas opções de escolha com relação aos trabalhos a serem desenvolvidos & \\
\hline IAA1 & Utiliza exemplos para ilustrar o que está sendo abordado em classe & \multirow{8}{*}{$\begin{array}{c}\text { Interesse pela } \\
\text { Aprendizagem do } \\
\text { Aluno }\end{array}$} \\
\hline IAA2 & Está disposto a elucidar dúvidas dos alunos & \\
\hline IAA3 & Proporciona ampla bibliografia relativa aos tópicos abordados & \\
\hline IAA4 & Desperta o interesse dos alunos pelo conteúdo ministrado & \\
\hline IAA5 & Tem disponibilidade para atender os alunos fora de sala de aula & \\
\hline IAA6 & Apresenta situações-problema a serem solucionadas pelos alunos & \\
\hline IAA7 & Expõe o conteúdo de uma maneira didática & \\
\hline IAA8 & Dá feedback construtivo aos alunos & \\
\hline
\end{tabular}


IAA9 Oferece informações importantes e interessantes relativas ao conteúdo da disciplina

IAA10 Tem entusiasmo pela disciplina que leciona

IAA11 Tem expectativas positivas com relação ao desempenho dos alunos

IAA12 Apresenta conteúdo atualizado 